\title{
EMG analysis of the influence of a water environment on the rehabilitation of patients with Parkinson's disease
}

\author{
Kateřina Lorencová*, Dagmar Pavlů, David Pánek
}

Faculty of Physical Education and Sport, Charles University, Prague, Czech Republic

* Corresponding author: kkotalikova@gmail.com

\begin{abstract}
The main goal of the experiment was to compare electrical activity in selected muscles: $m$. tibialis anterior, m. gastrocnemius, $m$. rectus femoris, $m$. biceps femoris and $\mathrm{mm}$. erectores spinae, at the $\mathrm{TH} / \mathrm{L}$ transition level patients with Parkinson's disease when walking on dry land and in a water environment, using surface electromyography.

The experimental set consisted of five subjects, two men and three women, aged $67.4 \pm 7.1$. A surface EMG was used to measure muscle activity in the $\mathrm{m}$. tibialis anterior, $\mathrm{m}$. gastrocnemius, $\mathrm{m}$. rectus femoris, $\mathrm{m}$. biceps femoris and $\mathrm{mm}$. erectores spinae at the $\mathrm{TH} / \mathrm{L}$ transition level. The resultant EMG signal was rectified and then the normalized muscle activity level was evaluated for walking in various environments: on dry land and in water.

Results showed identical normalized activity of monitored muscles in a water environment, which indicates a permanent effect of the pathological central programme accompanying Parkinson's disease, where the coordination pattern typical for a water environment fails to occur.
\end{abstract}

\section{KEYWORDS}

walking/gait; Parkinson's disease; aqueous environment; surface EMG; WaS EMG

D0I

$10.14712 / 23366052.2018 .9$

(C) 2018 The Authors. This is an open-access article distributed under the terms of the Creative Commons Attribution License (http://creativecommons.org/licenses/by/4.0), which permits unrestricted use, distribution, and reproduction in any medium, provided the original author and source are credited. 


\section{INTRODUCTION}

Flawless gait depends on a combination of perfect balance, coordination of motion and information on our surroundings obtained through our senses, such as sight and perceptions providing us with information about the terrain (Mečír, 1997). Gait is complex sequential phased motion taking place according to certain timing. This movement involves the entire motoric system, thus perfectly adapting to the complex characteristics and shape of the terrain in which we are walking. Gait occurs as a rhythmic pendulum-like translation of the body. It begins at an initial position, describes an arc via a zero point to one extreme position, and continues to the next extreme position. Clearly separated gait phases occur (Véle, 2006). Both legs go through three separate phases of movement. The swing phase - the leg moves forward without contact with the underlay, the stance phase - the leg is in contact with the support surface, also called the single support phase, and the double support phase, during which both legs are simultaneously in contact with the support base (Cuccurullo, 2009). Gait is one of the activities most often evaluated with EMG. In light of its high variability of muscle activity during each step for each individual, it is good to measure at least 6-10 steps to determine average values for selected parameters. Each individual has a characteristic gait speed that may affect surface EMG, which is why speed is standardized using a metronome or with a pre-set speed on a treadmill (Hug, 2011).

Gait in water is quite different from gait on ground, depending on immersion depth as well as whether the water is moving or not. The deeper the immersion, the lower the weight force due the Archimedes' Law, which also reduces the effect of the reactive force needed for support. Simultaneously the resistance of the environment increases, which is higher than air resistance. Gait patterns in water are quite different, which is why a water environment cannot be used for re-education of walking on dry land (Véle, 2006; Miyoshi et al., 2004; Masumoto et al., 2004; Veneziano et al., 2006; Shono et al., 2007; Kaneda et al., 2008).

Those with Parkinson's disease walk more slowly in comparison with healthy individuals, the duration of the gait cycle and individual gait phases is longer, the ratio between the supported and unsupported phase shifts toward the support phase, and the duration of the double support phase is longer than in healthy individuals (Dupalová et al., 2005). Patients with Parkinson's disease have shorter steps and drag their feet. When practicing walking, it is especially important to include rhythmic elements in the exercise. Walking is often practiced to music or as marching, or accompanied by the therapist's rhythmic and energetic commands (Tupá, 2013). Equally important is the therapist's guidance in maintaining step length, gait regularity, lifting of the knees, attendant movement of the arms, and ensuring the patient does not shorten his steps and does not return to poor gait stereotypes. The therapist's supervision and vocal stimulation of the patient is very important. External voice or other sound stimuli were found to have a positive effect. The effects of rhythm lasted even after dopamine medication was discontinued (Ressner \& Šigutová, 2001). Having to overcome visual barriers and walk along marked routes is also useful during training. The use of aids is possible, e.g. various sizes of balls thrown rhythmically to the ground, or kicking balls or other objects alternately in front of oneself (Dupalová et al., 2005). Treadmills can also be used to practice walking. This training has an effect on the manifestation 
of motor skills in patients with Parkinson's disease (Cakit, 2007; Herman, 2007, 2009; Hong, 2008; Lo, 2010; Miyai, 2002; Pelosin, 2009; Pohl, 2003).

Swimming and exercise in pools is recommended as a suitable activity for Parkinson's patients (Kolář et al., 2009; O’Nihill et al., 2001; Haggerty, 2009; Rosenstein, 2008), and the Parkinson Society also organizes pool exercises in its clubs. The American Parkinson Disease Association (http://www.apdaparkinson.org) also states that water is an excellent environment for anyone diagnosed with Parkinson's disease. The water's buoyancy gives the human body a feeling of freedom and release, and of easier movement. Exercise in water is promoted especially as a way to prevent falls and resultant injuries, and of strengthening of the posture muscles and releasing rigidity (O'Nihill et al., 2001; Haggerty, 2009). In her book on exercise in pools for Parkinson's patients, Rosenstein (2008) writes that any exercise, especially in water, helps the body improve stability and problems with walking, as well as improving their sense of well-being. He also states that patients whose hamstring strength is less than $2 / 3$ that of the quadriceps are more prone to falls. When the quadriceps is stronger, the body is pushed forward, causing instability. This is why it is important to keep the strength of the front and rear thigh muscles in equilibrium, thus improving patients' stability. We can achieve this through exercise in water, because this causes muscles to work in pairs - for each muscle that pulls back, the opposing muscle pulls forward. It is estimated that water increases body resistance by $12-14 \%$.

Most published works in the area of a water EMG deal with normal or modified gait. In dynamic modes, it is recommended that movement in water be performed at half the rate it is on land. The greater viscosity of water compared to air can lead to changes in EMG records, especially during more rapid movements. Water temperature is also important. Optimum water temperature is between 27 and $34{ }^{\circ} \mathrm{C}$. Colder water leads to reduced electrical activity in muscles. Warmer water is unpleasant for performance of movement (Pánek et al., 2012; Miyoshi et al., 2004; Masumoto et al., 2004; Veneziano et al., 2006; Shono et al., 2007; Kaneda et al., 2008).

\section{METHODOLOGY}

This paper is an analytic experimental study that includes an experiment focusing on the difference of normalized EMG activity of selected muscles while walking in water and on dry land for subjects with Parkinson's disease.

\section{Research set}

Five subjects with Parkinson's disease aged 67.4 \pm 7.1 participated in the experiment. Parkinson's was diagnosed at an average age of 57, and the set contained three women and two men. All of the subjects stated that they attend group exercise organized by the Parkinson Society once per week. None of the subjects reported increased fatigue, pain or a high degree of fatigue, and they were medicated as per usual.

\section{Methods used}

In the experiment, a telemetric 16-channel TelemyoMini 16 EMG instrument from Neurodata was used, which in basic configuration includes its own EMG instrument, a transmitter with an amplifier connected to bipolar electrodes, and two independent 
antennas for receiving signals from the transmitter; a video camera was simultaneously used to record the subject's movement. Additional equipment was required to record EMG signals in water: a waterproof ouch for the EMG amplifier and transmitter, special bipolar electrodes with a set of double-sided adhesive collars required to firmly adhere the electrodes to skin, waterproof covering adhesive stickers for electrodes, EMG conducting gel, universal multi-use silicon (Pánek et al., 2010) and Patex carpet tape.

\section{Applications of electrodes to skin}

Special bipolar electrodes are used to record EMG signals in water. They are AG/ $\mathrm{AgCl}$ disk electrodes $5 \mathrm{~mm}$ in diameter, encased in plastic so that only the central part that contacts the skin is left exposed. As the electrodes should be placed on well-cleaned and degreased skin, we used abrasive paste and petrol alcohol. We applied double-sided adhesive tape to the plastic electrode disk, which copies the electrode's round shape and is supplied along with the electrodes. We then applied a conducting paste to the electrode. It is very important to apply the correct amount: if there is too much the electrode can come loose, while if there is too little, the electrical signal can be weak or nonexistent. To securely attach the electrode to the skin, it is covered by a special round adhesive patch with a central opening that is positioned precisely above the electrode, and also covers the electrode cable. Experience shows that individual covering patches can overlap by approximately $1 / 3$ of their diameter, which maintains optimum electrode spacing (Pánek et al., 2010). We had good results with also covering electrodes and preamplifiers with carpet tape for increased water resistance and to reduce the likelihood of electrodes coming loose.

In light of work in a moist environment, the EMG instrument and laptop must be protected from damage.

\section{Data collection Muscle selection}

Muscle activity in the right leg was recorded: $\mathrm{m}$. gastrocnemius, $\mathrm{m}$. tibialis anterior, $\mathrm{m}$. biceps femoris, and $\mathrm{m}$. rectus femoris. Potentials in the paravertebral muscles at the $\mathrm{TH} / \mathrm{L}$ transition level were recorded bilaterally.

\section{Electrode placement}

The electrodes were placed along the centreline of the muscle belly for the aforementioned muscles. A ground (reference) electrode was placed in the $\mathrm{C} 7$ spinous process area.

\section{The experiment}

The experiment was performed at the FLUM - training pool of the Faculty of Physical Education and Sport of Charles University, with a water temperature of $32{ }^{\circ} \mathrm{C}$. Measurements were performed over the course of one day, and were preceded by the collection of important medical history data using a questionnaire. We applied special bipolar surface electrodes for recording in water to the subject, on selected leg and paravertebral muscles as specified above. Initially, maximum voluntary contraction (MVC) measurements were performed out of the water for all muscles according to 


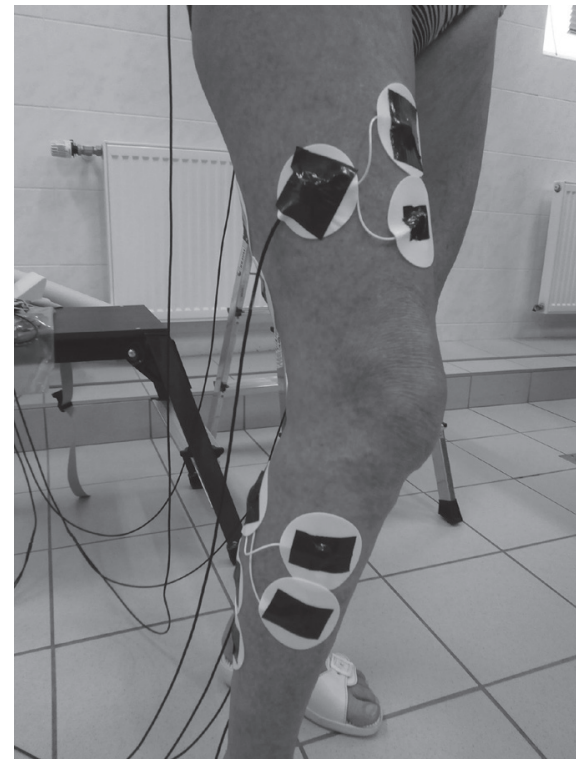

Figure 1 Electrode application

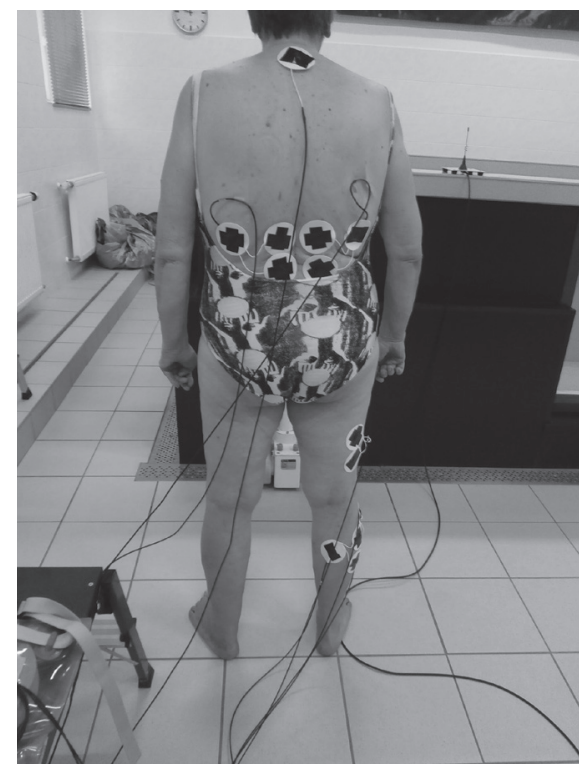

Figure 3 Electrode placement - rear view

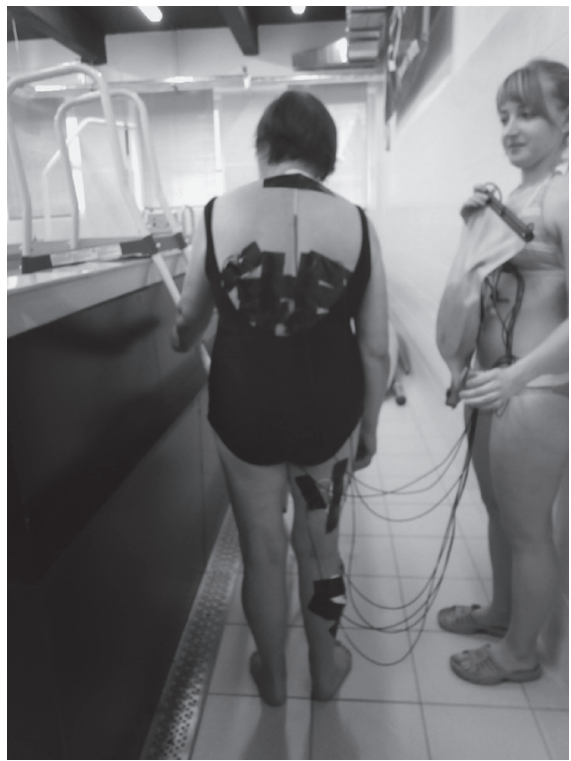

Figure 2 Securing the electrodes with carpet/duct tape

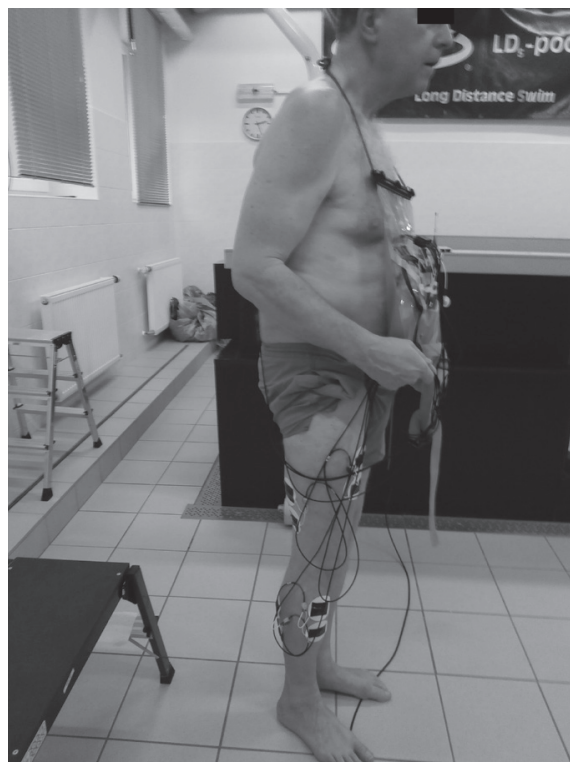

Figure 4 Electrode placement - side view

defined positions in the muscle test. Each of the subjects was asked to perform maximum contraction against resistance, $3 \times$ in a row. The maximum contraction lasted $10 \mathrm{~s}$, and there were 2 -minute pauses between individual maximum contractions. 
Measurement was split in two parts.

1) The subject was asked to walk on dry land for $15 \mathrm{~m}$ at 70 steps per minute to the ticking of a metronome. The EMG recorded the activity of selected muscle groups.

2) The subject entered the pool (water depth $120 \mathrm{~cm}$ ) using the access stairs and accompanied by a measurement assistant; he was once again asked to walk to a metronome at a rate of 40 steps per minute. The assistant held the pouch with the EMG receiver steady in order to reduce the number of artefacts caused by cable movement. The EMG recorded the activity of selected muscle groups. Afterwards, the subject exited the pool using the steps.

It was necessary to check the electrodes prior to immersion, as after contact with water it would have been impossible to reapply them.

\section{Data analysis - statistical data processing}

MyoResearch XP Master Edition 1.08.27 software from NORAXON was used to evaluate and process the resultant data. This application allows the EMG signal to be viewed in synchronization with the video recording, allowing a visual check to be performed during evaluation. Artefacts were first removed from the signal, which was then rectified and smoothed. Maximum voluntary contraction (MVC) was evaluated from three maximum $2 \mathrm{~s}$ intervals of a stabilized EMG signal in each $10 \mathrm{~s}$ of measurement. These values were averaged to obtain the resulting MVC.

\section{RESULTS}

The EMG data obtained was processed as recommended by Hug (2011). We selected six consecutive step cycles. Each cycle began with the double support phase, when

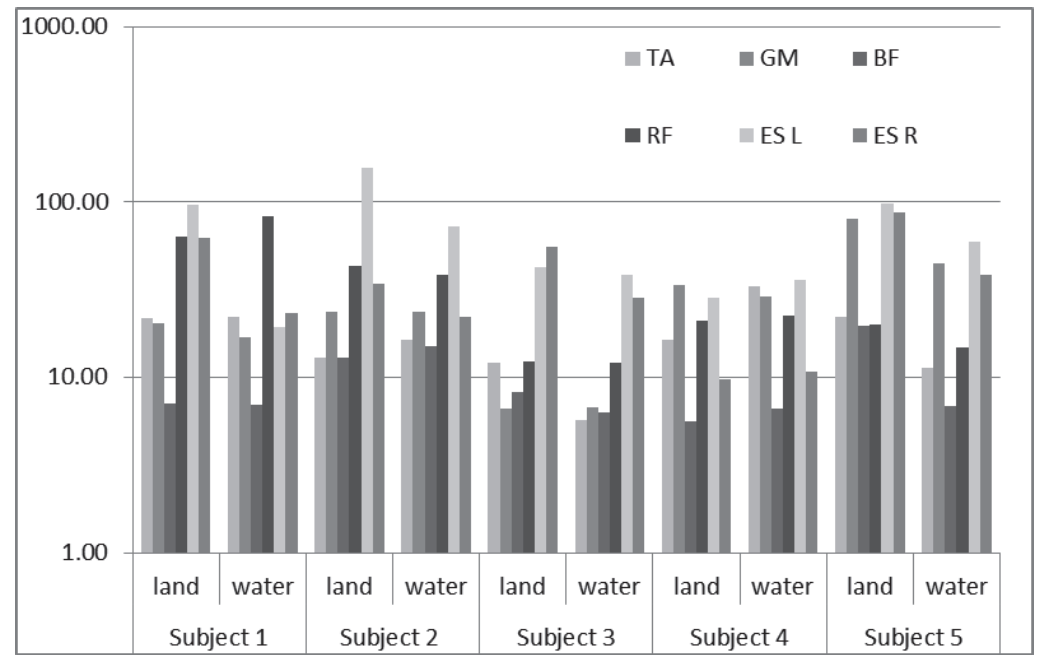

Figure 5 Normalized EMG activity values for selected muscles for all subjects when walking on dry land and in water, where $\mathrm{TA}=\mathrm{m}$. tibialis anterior, $\mathrm{GM}=\mathrm{m}$. gastrocnemius, $\mathrm{RF}=\mathrm{m}$. rectus femoris, $\mathrm{BF}=\mathrm{m}$. biceps femoris, $\mathrm{ES} \mathrm{L} / \mathrm{R}=\mathrm{mm}$. erectors spinae left/right 
the tip of the support (recorded) leg was being rolled up, and ended with the rolling up of the support leg of the next step. The beginning and end of the cycle in the EMG signal was defined by the beginning of $\mathrm{m}$. tibialis anterior activity. The signal was then rectified and the mean amplitude over six step cycles obtained. The mean amplitude was normalized to maximum voluntary contraction (mean/MVC $\times 100)$. All recorded muscles were evaluated in this way, and then were compared against each other using Pearson's correlation. Correlation was also performed from normalized values for identical muscles in various environments.

Table 1 Normalized EMG activity values for selected muscles for all subjects when walking on dry land and in water, where $T A=m$. tibialis anterior, $G M=m$. gastrocnemius, $R F=m$. rectus femoris, $B F=m$. biceps femoris, $E S L / R=m m$. erectors spinae left/right

\begin{tabular}{lcccccccccc}
\hline & \multicolumn{2}{c}{ Subject 1 } & \multicolumn{2}{c}{ Subject 2 } & \multicolumn{2}{c}{ Subject 3 } & \multicolumn{2}{c}{ Subject 4 } & \multicolumn{3}{c}{ Subject 5 } \\
& land & water & land & water & land & water & land & water & land & water \\
\hline TA & 21.64 & 21.96 & 12.88 & 16.33 & 12.07 & 5.69 & 16.29 & 33.10 & 22.12 & 11.31 \\
GM & 20.32 & 16.84 & 23.55 & 23.77 & 6.68 & 6.76 & 33.81 & 28.94 & 80.05 & 44.77 \\
BF & 7.12 & 6.94 & 12.98 & 15.19 & 8.28 & 6.34 & 5.62 & 6.64 & 19.53 & 6.90 \\
RF & 63.00 & 82.73 & 43.43 & 38.53 & 12.32 & 12.16 & 21.14 & 22.47 & 19.86 & 14.87 \\
ES L & 95.95 & 19.30 & 156.06 & 72.85 & 42.56 & 38.23 & 28.27 & 36.00 & 98.26 & 59.19 \\
ES R & 62.17 & 23.22 & 34.03 & 22.05 & 55.71 & 28.47 & 9.78 & 10.87 & 87.25 & 38.31 \\
\hline & Subject 1 & Subject 2 & Subject 3 & Subject 4 & Subject 5 \\
\hline & land & water & land & water & land & water & land & water & land & water \\
TA & 21.64 & 21.96 & 12.88 & 16.33 & 12.07 & 5.69 & 16.29 & 33.10 & 22.12 & 11.31 \\
GM & 20.32 & 16.84 & 23.55 & 23.77 & 6.68 & 6.76 & 33.81 & 28.94 & 80.05 & 44.77 \\
BF & 7.12 & 6.94 & 12.98 & 15.19 & 8.28 & 6.34 & 5.62 & 6.64 & 19.53 & 6.90 \\
RF & 63.00 & 82.73 & 43.43 & 38.53 & 12.32 & 12.16 & 21.14 & 22.47 & 19.86 & 14.87 \\
ES L & 95.95 & 19.30 & 156.06 & 72.85 & 42.56 & 38.23 & 28.27 & 36.00 & 98.26 & 59.19 \\
ES R & 62.17 & 23.22 & 34.03 & 22.05 & 55.71 & 28.47 & 9.78 & 10.87 & 87.25 & 38.31 \\
\hline
\end{tabular}

Table 2 P-value TAl $-\mathrm{TAw}=\mathrm{m}$. tibialis anterior on dry land $-\mathrm{m}$. tibialis anterior in water, $\mathrm{GMI}-\mathrm{GMw}=\mathrm{m}$. gastrocnemius on dry land $-\mathrm{m}$. gastrocnemius in water, $\mathrm{RFI}-\mathrm{RFw}=\mathrm{m}$. rectus femoris on dry land $-\mathrm{m}$. rectus femoris in water, $\mathrm{BFI}-\mathrm{BFW}=\mathrm{m}$. biceps femoris on dry land $-\mathrm{m}$. biceps femoris in water

\begin{tabular}{ll}
\hline Muscle I/w & P-value \\
\hline GMI-GMw & 0.004942 \\
TAI-TAw & 0.6301 \\
RFI-RFw & 0.003256 \\
BFI-Bfw & 0.3432 \\
\hline
\end{tabular}




\section{Comparison of muscle activity when walking on dry land and in water}

Analysis results showed that for four subjects (1-4), leg muscle activity was unchanged when walking in water as compared to dry land, but subject 1 exhibited a $20 \%$ increase in activity of $\mathrm{m}$. rectus femoris. Similarly, subject 4 differs from the others in having increased activity in $\mathrm{m}$. tibialis anterior. Subjects 2 and 3 had no change in $\mathrm{m}$. gastrocnemius activity whatsoever (see Figure 6). Subject 1 also had no changes in activation of $\mathrm{m}$. tibialis anterior and $\mathrm{m}$. biceps femoris due to environment. On average, muscle activity in Parkinson's patients increased by $1.5 \%$ in water. It was statistically proven that for subjects 1-4, m. gastrocnemius activity in a changed environment remained the same ( $\mathrm{p}$-value $=0.004942$ ). In subjects $1-4, \mathrm{~m}$. rectus femoris also exhibits significant statistical correlation between activity on dry land and in water ( $\mathrm{p}$-value $=$ 0.003256 ). Subject 5 exhibited a mean reduction in muscle activity of $16 \%$, with the greatest difference in activity on dry land and in water (35\% more in water) being exhibited by $\mathrm{m}$. gastrocnemius. Subjects also had variable participation of paravertebral muscles, but except for subject 4 , their activity declined in water by an average of $30 \%$. The different activities of paravertebral muscles in subject 4 from others in the set, as far as percent difference when walking on dry land and in water is concerned, could be caused by the fact that he was significantly taller than the rest.

The above results thus show comparable activity when walking on dry land and in the water for subjects $1-4$ in the $\mathrm{m}$. tibialis anterior, $\mathrm{m}$. gastrocnemius, $\mathrm{m}$. rectus femoris and $\mathrm{m}$. biceps femoris, which was the main focus of the experiment. For paravertebral muscles, individuals exhibited significant difference, but overall their activity declined in water.

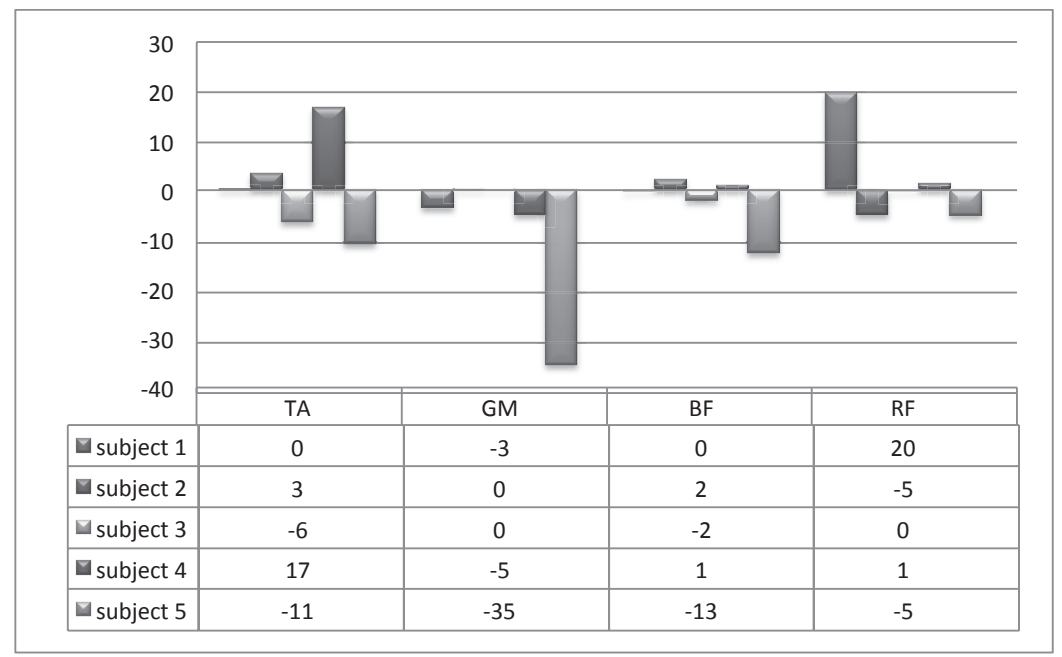

Figure 6 Percent difference in muscle activity (TA, GM, RF, BF) for individual subjects when walking on dry land and in water, where $\mathrm{TA}=\mathrm{m}$. tibialis anterior, $\mathrm{GM}=\mathrm{m}$. gastrocnemius, $\mathrm{RF}=\mathrm{m}$. rectus femoris, $\mathrm{BF}=\mathrm{m}$. biceps femoris, and where the $y$-axis scale is in \% 


\section{DISCUSSION}

Swimming and exercise in pools is recommended as a suitable activity for Parkinson's patients (Kolár et al., 2009; O’Nihill et al., 2001; Haggerty, 2009; Rosenstein, 2008; ADPA), but more detailed studies on have not been done in this area. Our EMG study focused on comparing differences in electrical muscle activity when walking on dry land and in water for patients with Parkinson's disease. Walking speed in water was $40 \mathrm{steps} / \mathrm{min}$, where the water level was up to the proc. xiphoideus, and 70 steps/min on dry land. Our results did not prove a trend towards reduced leg muscle activity when walking in water as it is in the healthy population regardless of age, as stated by Masumoto et al. (2004, 2007a, 2007b, 2008) and Barela (2006). Fujisawa (1998) and Hollander (2011) also describe reduced electrical muscle activity during muscle activity in water, but these studies do not deal with walking in water. Barela (2006) showed in his study that the activation pattern in water did not change for the $\mathrm{m}$. gastrocnemius. This was also confirmed in this experiment, along with unchanged $\mathrm{m}$. rectus femoris activity in water, except for subject 5 . Subject 5 was in a more advanced phase of the illness than the others; he exhibited stiffness and prominent arm tremors. He was the last to be tested, and the effect of his chronic medication could have had a reduced effect. With Parkinson's patients it was difficult to affix electrodes securely in water due to their increased production of skin oils, which is related to the vegetative symptoms of Parkinson's disease (Pahwa, 2004; Berger et al., 2000; Roth et al., 2005, 2009). The results of the experiment show the serious impairment of motor control in patients with this diagnosis, because typical changes in movement patterns in water as described by Véle (2006), Masumoto et al. (2004, 2007a, 2007b, 2008 and Barela (2006) for healthy individuals did not occur. The effect of the pathological motor programme due to impaired basal ganglia function has a much stronger effect on movement behaviour than the effect of water on the biomechanical and kinetic behaviour of the afflicted individual. From the results obtained, we do not agree with Rosenstein's claim (2008) that exercise in water and practicing walking in water can increase muscle strength in patients with Parkinson's disease.

\section{CONCLUSION}

Regular movement therapy for patients with Parkinson's disease is as important as regular administration of drugs. Rehabilitation is generally recommended for patients with Parkinson's disease, but its effectiveness has not yet been fully proven. The results of our study indicate that in these patients, the contraction strategy of muscles does not change in water compared to movement on dry land. For this reason, rehabilitation in water does not provide any benefit for rehabilitation of Parkinson's patients over that on dry land, and the suitability of indicating this auxiliary treatment will to a great degree depend on the relationship of the given individual to water.

\section{ACKNOWLEDGEMENTS}

I would like to thank Parkinson's patients from the Parkinson o.s. association for participating in this experiment. 
This article was written within the institutional support of Charles University Progres Q41.

\section{REFERENCES}

ADPA - American Parkinson Disease Association [online]. 2013 [cit. 2014-02-23]. Available from: http://www.apdaparkinson.org.

Barela, A. M. F., Stolf, S. F., \& Duarte, M. (2006). Biomechanical characteristics of adults walking in shallow water and on land. Journal of Electromyography and Kinesiology, 16(3), 250-256.

Berger, J., Kalita, Z., \& Ulč, I. (2000). Parkinsonova choroba. Prague: Maxdorf.

Cakit, B. D., Saracoglu, M., Genc, H., Erdem, H. R., \& Inan, L. (2007). The effects od incremental speed-dependend treadmill training on postural instability and fear of ffalling in Parkinsons disease. Clinical Rehabilitation, 21(8), 698-705.

Cuccurullo, S. J. (2009). Physical medicine and rehabilitation board review. 2nd ed. New York: Demos Medical.

Dupalová, D., Opavský, J., \& Janečková, K. (2005). The effect of physiotherapy on selected characteristics of gait in patients with Parkinson's disease. Rehabilitace a fyzikální lékařství, 12(2), 129-133.

Fujisawa, H., Suenaga, N., \& Minami, A. (1998). Electromyographic study during isometric exercise of the shoulder in head-out water immersion. Journal of Shoulder and Elbow Surgery, 7(5), 491-494.

Haggerty, M. (2009). Dystonia and Parkinson's Aquatic Techniques. In: Dystonia and Parkinson's Aquatic Techniques [online]. [cit. 2013-03-23].

Herman, T., Giladi, N., Gruendlinger, L., \& Hausdorff, J. M. (2007). Six weeks of intensive treadmill training improves gait and quality of life in patients with Parkinson's disease: a pilot study. Archives of Physical Medicine and Rehabilitation, 88(9), 1154-1158.

Herman, T., Giladi, N., \& Hausdorff, J. M. (2009). Treadmill training for the treatment of gait disturbances in people with Parkinson's disease: a mini-review. Journal of Neural Transmission, 116(3), 307-318.

Holländerová, D., Pavlů, D., \& Pánek, D. (2012). Hodnocení EMG aktivity horní části m. trapezius při cviku proti pružnému odporu ve vodním prostředí a na suchu. Rehabilitace a fyzikální lékařství, 19(1), 35-41.

Hong, M., \& Earhart, G. M. (2008). Rotating treadmill training reduces freezing in Parkinson disease: Preliminary observations. Parkinsonism, 14(4), 359-363.

Hug, F. (2011). Can muscle coordination be precisely studied by surface electromyography? Journal of Electromyography and Kinesiology 21(1), 1-12.

Kaneda, K., Wahabayashi, H., Sato, D., Uekusa, T., \& Nomura, T. (2008). Lower extremity muscle activity during deep-water running on self-determined pace. Journal of Electromyography and Kinesiology, 18(6), 965-972.

Kolář, P., et al. (2009). Rehabilitace v klinické praxi. 1st ed. Prague: Galén.

Lo, A. C., Chang, V. C., Gianfrancesco, M. A., Friedman, J. H., Patterson, T. S., \& Benedicto, D. F. (2010). Reduction of freezing of gait in Parkinson's disease by repetitive robot-assisted treadmill training: a pilot study. Journal of NeuroEngineering and Rehabilitation, 7(1), 51.

Masumoto, K., Takasugi, S., Hotta, N., Fujishima, K., \& Iwamoto, Y. (2004). Electromyographic Analysis of Walking in Water in Healthy Humans. Journal of Physiological Anthropology and Applied Human Science, 23(4), 119-127.

Masumoto, K., Shono, T., Takasugi, S., Hotta, N., Fujishima, K., \& Iwamoto, Y. (2007a). Age-related differences in muscle activity, stride frequency and heart rate response during walking in water. Journal of electromyography and kinesiology: official journal of the International Society of Electrophysiological Kinesiology, 17(5), 596-604. 
Masumoto, K., Takasugi, S., Hotta, N., Fujishima, K., \& Iwamoto, Y. (2007b). A comparison of muscle activity and heart rate response during backward and forward walking on an underwater treadmill. Gait, 25(2), 222-228.

Masumoto, K., \& Mercer, J. (2008). Biomechanics of human locomotion in water: an electromyographic analysis: methodological considerations for quantifying muscle activity during water locomotion. Exercise and Sport Sciences Reviews, 36(3), 160-169. Available from: http://www.medscape.com/viewarticle/576869_5.

Mečír, P. (1997). Poruchy chůze u Parkinsovy nemoci. Parkinson: časopis Společnosti Parkinson, 2, 6-7.

Miyai, I., Fujimoto, Y., Yamamoto, H., Ueda, Y., Saito, T., Nozaki, S., \& Kang, J. (2002). Longterm effect of body weight-supported treadmill training in Parkinson's disease: A randomized controlled trial. Archives of Physical Medicine and Rehabilitation, 83(10), 1370-1373.

Miyoshi, T., Shirota, T., Yamamoto, S., Nakazawa, K., \& Akai, M. (2004). Effect of the walking speed to the lower limb joint angular displasments, joint movements and ground reaction force during walking in water. Disability \& Rehabilitation, 26(12), 724-732.

O’Nihill, A. E. P., Cothran, C., \& Habermann, B. (2001). Aquatic excercise for Parkinson's disease: A guide for patients and their families. Aquatic Handbook [online].The American Parkinson Disease Association. Available from: http://www.parkinsonswny.com/Aquatic -Handbook.pdf.

Pahwa, R., Lyons, K. E., \& Koller, W. C. (2004). Therapy of Parkinson's disease. Neurological disease and therapy. 3rd ed. New York: M. Dekker.

Pánek, D., Pavlů, D., \& Čemusová, J. (2012). EMG methods for evaluating muscle and nerve function: water surface electromyography. 1st ed. Rijeka: Intech, 455-470.

Pánek, D., Jurák, D., Pavlů, D., Krajča, V., \& Čemusová, J. (2010). Metodika snímání povrchového EMG ve vodním prostředí. Rehabilitace a fyzikální lékařství, 17(1), 21-25.

Pelosin, E., Faelli, E., Lofrano, F., Avanzino, L., Marinelli, L., Bove, M., Ruggeri, P., \& Abbruzzese, G. (2009). Effects of treadmill training on walking economy in Parkinson's disease: a pilot study. Neurological Sciences, 30(6), 499-504. Available from: http://link.springer .com/10.1007/s10072-009-0141-8.

Pohl, M., Rockstroh, G., Rückriem, S., Mrass, G., Mehrholz, J., Bove, M., Ruggeri, P., \& Abbruzzese, G. (2003). Immediate effects of speed-dependent treadmill training on gait parameters in early Parkinson's disease: a pilot study. Archives of Physical Medicine and Rehabilitation, 84(12), 1760-1766.

Ressner, P., \& Šigutová, D. (2001). Léčebná rehabilitace u Parkinsonovy nemoci. Neurologie pro praxi, 1, 31-35. Available from: http://www.solen.sk/pdf/Ressner.pdf.

Rosenstein, A. A. (2008). Water exercises for Parkinson's: maintaining balance, strength, endurance, and flexibility. Rev. ed. Enumclaw, WA: Idyll Arbor.

Roth, J., Sekyrová, M., \& Rủžička, E. (2005). Parkinsonova nemoc. 3rd ed. Prague: Maxdorf. Roth, J., Sekyrová, M., \& Rủžička, E. (2009). Parkinsonova nemoc. 4th ed. Prague: Maxdorf. Shono, T., Masumoto, K., Fujishima, K., Hotta, N., Ogaki, T., \& Adachi, T. (2007). Gait patterns and muscle activity of the lower extremities of elderly women during underwater treadmill walking againts water flow. Journal of Physiological Anthropology, 26(6), 579-586.

Tupá, V., Pánek, D., \& Pavlů, D. (2013). Alternative therapeutic approaches in patients with Parkinson's disease. Rehabilitace a fyzikální lékařství, 20(1), 35-42.

Véle, F. (2006). Kineziologie: přehled klinické kineziologie a patokineziologie pro diagnostiku a terapii poruch pohybové soustavy. 2nd ed. Prague: Triton.

Veneziano, W., da Rocha, A., Goncalves, C., Pena, A., Carmo, J., Nascimento, F., \& Rainoldi, A. (2006). Confounding factors in water EMG recordings: an approach to a definitive standard. Medical \& Biological Engineering \& Computing, 44(4), 348-351. 